\title{
WIRELESS POWER TRANSFER VIA INDUCTIVE COUPLING
}

Mirsad Hyder Shah

Ex-Fellow, Department of Electrical Engineering, DHA Suffa University. Karachi, (Pakistan). E-mail: itsmirsadhyder@yahoo.com ORCID: https://orcid.org/0000-0003-2476-5887

Nasser Hassan Abosaq

Assistant Professor, Computer Science and Engineering Department. Yanbu University College, Yanbu Industrial City, (Saudi Arabia). E-mail: abosaqn@rcyci.edu.sa ORCID: https://orcid.org/0000-0003-1354-3170

\section{Citación sugerida Suggested citation}

Shah, M. H., y Abosaq, N. H. (2020). Wireless power transfer via inductive coupling. 3C Tecnología. Glosas de innovación aplicadas a la pyme. Edición Especial, Abril 2020, 107-117. http://doi. org/10.17993/3ctecno.2020.specialissue5.107-117 


\section{ABSTRACT}

The concept of transferring electrical power to a load wirelessly is an intimidating and a challenging idea. The genius of powering systems wirelessly has pulled the curtains to a new world. In the $19^{\text {th }}$ century, Nikola developed 'Tesla Tower' in hope to transfer power wirelessly. Since then, the world is trying hard to say goodbye to wires. WPT using Inductive Coupling which falls under the domain of NFWPT, uses a transmitter coil to transmit power to the receiver coil via a magnetic field. Inductive coupling is an efficient way to transmit power through short distances and making its way in smartphones and the health industry. Electric vehicle charging stations are also trending thanks to wireless power transfer. This paper discusses the theoretical foundation of Inductive coupling and presents results of an experimental work done on WPT via Inductive Coupling. In the process above, an efficiency of $72 \%$ was achieved.

\section{KEYWORDS}

Wireless Power Transfer, Inductive Coupling. 


\section{INTRODUCTION}

Many Engineers and Physicists credit Nikola Tesla for the concept of wireless power transfer, ignoring Faraday being the pioneer of the concept of transferring energy wirelessly when he demonstrated how Electromotive-Force and Current were induced in a conductor when subjected to a changing magnetic field, and hence the concept of Wireless Power Transfer was derived. In 1892, Nikola Tesla believed wireless power transfer was possible and began building what he called the 'Tesla Tower'. This 200 feet high tower was energized with $300 \mathrm{~kW}$ of power but couldn't prove to succeed because of the long distance approach (Johnson, 1990). The late $19^{\text {th }}$ century saw an attempt to power electric vehicles through electrodynamic induction, but combustion engines proved much more efficient. In 1978, the United States powered an electrical vehicle successfully; while in 1987, Canada successfully flew the first fuel-free airplane model. Commercial use of powering smartphones wirelessly came up on the scene after 2009, when Palm Inc. introduced wireless charging in their smartphones. Samsung and Apple followed the lead and presented wireless charging in 2013 and 2014 respectively.

\subsection{RESEARCH SIGNIFICANCE}

Wirless power transfer is the dawn of a new age. At present, many companies have introduced commercial use of wireless charging for smartphones, EV cars and other electronic devices. Wireless Power Transfer has even made its mark in the healthcare, especially in the implantable medical devices. This study presents a simple prototype which can be employed for smartphones or cars with an impressive efficiency of $72 \%$ when placed in proximity.

\subsection{OVERVIEW OF WPT}

Wireless power transfer can be classified into two fields; NFWPT (Near Field Wireless power technology) and FFWPT (Far Field Wireless power technology) (Hassan \& Elzawawi, 2015).

NFWPT is further classified as electromagnetic induction, as it depends on the coupling of the magnetic-field between the two coils, which explains why it has a short range. The field (range) of NFWPT decreases exponentially. It includes Inductive Power Transfer 
(IPT), Resonant Inductive Power Transfer, Capacitive Power Transfer (CPT), Resonant Capacitive Coupling and Magneto-dynamic coupling (Hassan \& Elzawawi, 2015).

FFWPT is further classified as electromagnetic radiation. It is most convenient for long range applications. But due to the power losses, it is comparatively less efficient. It includes lasers (radiowaves) and microwaves to transmit power.

Table 1. Classification of WPT technologies.

\begin{tabular}{|c|c|c|c|c|}
\hline $\begin{array}{c}\text { WPT } \\
\text { Technolgies }\end{array}$ & Range & Frequency & Efficiency & Power transfer via \\
\hline NFWPT & Short-Medium & $\mathrm{Hz}-\mathrm{kHz}$ & High & Electric or Magnetic Fields. \\
\hline FFWPT & Long & $\mathrm{MHz}$ & Low & $\begin{array}{c}\text { Infrared or Ultraviolet or } \\
\text { Microwaves }\end{array}$ \\
\hline
\end{tabular}

Source: (Hassan \& Elzawawi, 2015).

\section{WPT USING INDUCTIVE COUPLING}

Any Wireless Power Technology must have two core components for it to work; a transmitter and a receiver. In the case of Inductive Coupling, the transmitter and receiver are two separate coils wound on materials with high permeability. This increases the efficiency of the circuit by increasing the inductance of the coils. The transmitter transfers AC power to the receiver which can then be converted to DC for in use applications. As DC power transfer has higher energy loss hence the model comprises of transferring AC power.

In Inductive power transfer, longitudinally arranged dipole fields are produced. These fields decrease with the cube of distance between the transmitter and the receiver. Hence one of the factors affecting the efficiency is the distance between the two coils. Hence, the closer the receiver and the transmitter, the better the efficiency (Van Schuylenbergh \& Puers, 2009).

Inductive coupling solely involves magnetic fields for transferring power and therefore can be referred to as 'Magnetic coupling' as well. It works on the basic principle of faraday's law of induction which explains how a magnetic field will interact with an electrical circuit to produce an electromotive force (EMF) in the secondary coil. The power transfer in Inductive coupling is directly proportional to the frequency as well as the mutual inductance between the coils. The mutual inductance between the transmitter and receiver can be calculated by: 


$$
M=k \times \sqrt{\left(L_{1} \times L_{2}\right)}
$$

Where, $\mathrm{k}$ is the coupling coefficient. It is a dimensionless parameter.

Another factor which affects the efficiency of WPT is misalignment tolerance. Misalignment is the displacement of the receiver coil with respect to the transmitter coil that leads to a decline in both the efficiency and power transfer of the IPT system. Since,

$$
\phi_{B}=\iint_{0}^{A} \vec{B} \cdot d \vec{A}
$$

For maximum flux, the dot product requires the angle between the flux density $(\vec{B})$ and the area enclosed to be $0 \mathrm{deg}[\cos 0=1]$. This can be ensured when both the transmitter and receiver coils overlap each other.

Graphic 1 shows the basic model of a complex circuit which transfers power via inductive coupling. The transmitter consists of an AC voltage source $\left(\mathrm{V}_{\mathrm{p}}\right)$ and a primary coil $\left(\mathrm{L}_{\mathrm{p}}\right)$ on the left hand side, while the receiver consists of a secondary coil $\left(\mathrm{L}_{\mathrm{s}}\right)$ and $\mathrm{R}_{\text {load }}$. A bridge rectifier and further electronic circuitry are lumped as $\mathrm{R}_{\text {load }}$ on the right hand side. The transmitter is powered through an AC source (a coil driver) which produces a magnetic flux in the primary coil. This induces a voltage in $\mathrm{L}_{\mathrm{p}}$ which in turn produces a flux in the secondary coil $\mathrm{L}_{\mathrm{s}}$. This flux produces a voltage in the secondary coil which can be rectified for further use (Van Schuylenbergh \& Puers, 2009).
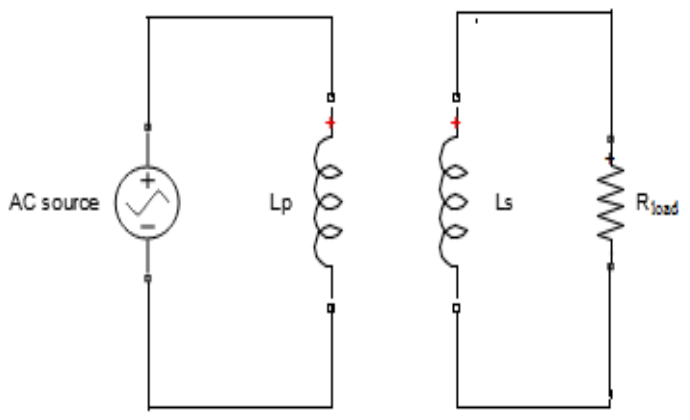

Graphic 1. Basic circuit diagram of WPT using inductive coupling. Source: (Van Schuylenbergh \& Puers, 2009). 
To calculate the link efficiency of the coupling circuit, Graphic 2 is used. Since, Graphic 1 is a generalized block of Graphic 2; it neglects the coil resistances of the receiver and transmitter. From transformer theory, we know that the two coils employ the coupling coefficient $(\mathrm{k})$ and that both the inductances $\mathrm{L}_{\mathrm{p}}$ and $\mathrm{L}_{\mathrm{s}}$ are affected by $\mathrm{k}$.

From transformer theory we know that, reducing the circuit with respect to primary side will yield:
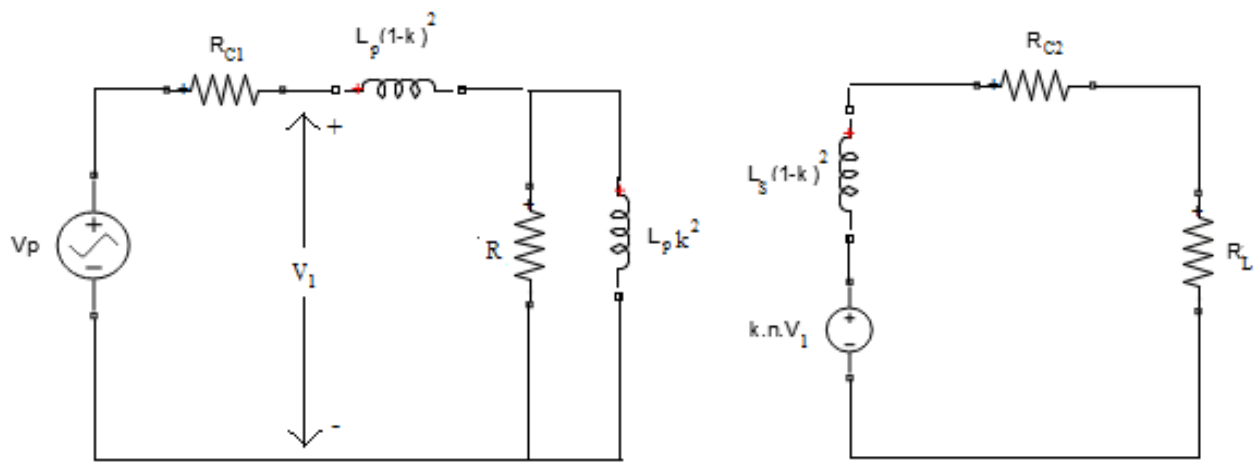

Graphic 2. Inductive circuit referred to the primary side and coil losses included. Source: (Van Schuylenbergh \& Puers, 2009).

Where,

$$
R=\left(\frac{k}{n}\right)^{2}\left(R_{\text {load }}+R_{c 2}\right)
$$
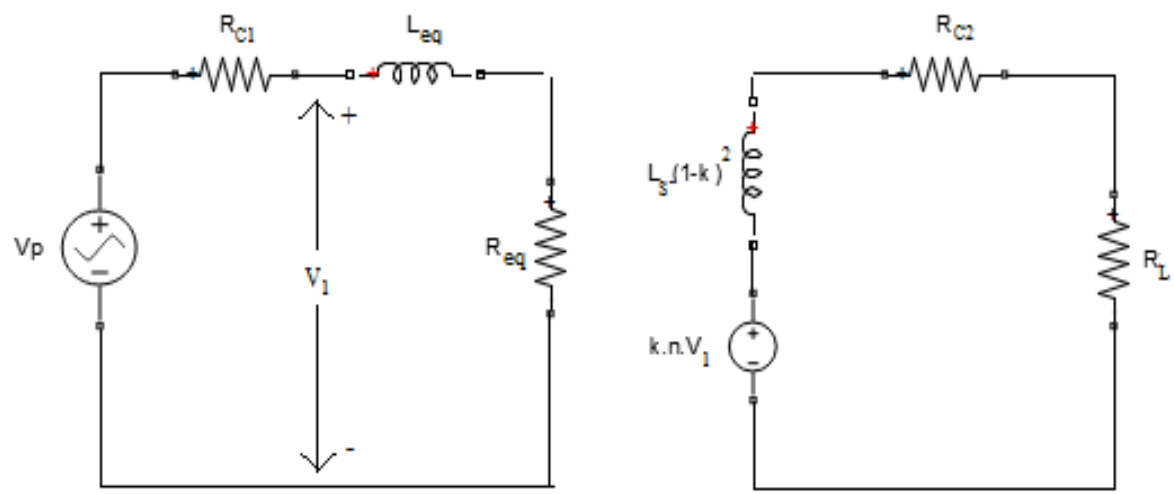

Graphic 3. Equivalent circuit for the calculation of link efficiency. Source: (Van Schuylenbergh \& Puers, 2009).

And the equivalent resistance and inductance are given by: 


$$
\begin{gathered}
L_{e q}=L_{p}\left[\frac{R^{2}+\omega^{2} L_{p}^{2} k^{4}\left(1-k^{2}\right)}{R^{2}+\omega^{2} L_{p}^{2} k^{4}}\right] \\
\mathrm{R}_{e q}=R\left[\frac{\omega^{2} L_{p}^{2} k^{4}}{R^{2}+\omega^{2} L_{p}^{2} k^{4}}\right]
\end{gathered}
$$

The link efficiency is given by,

$$
\begin{gathered}
\eta_{\text {link }}=\left(\frac{R_{e q}}{R_{e q}+R_{p}}\right)\left(\frac{R_{\text {loud }}}{R_{\text {load }}+R_{s}}\right) \\
\eta_{\text {link }}=\left(\frac{k}{n}\right)^{2} \frac{R_{\text {load }} \omega^{2} L_{p}^{2} k^{4}}{\left(R+R_{p}\right) \omega^{2} L_{s}^{2} k^{4}+R^{2} R_{p}}
\end{gathered}
$$

It can be observed that one of the factors the link efficiency is dependent on is the square of primary inductance of the coil. A higher value of mutual coupling ' $k$ ' is also desirable for better link efficiency (Van Schuylenbergh \& Puers, 2009).

\section{THEORY OF WPT}

According to amperes law, the loop integral of the $\vec{B}$ field equals the net current i enclosed by the loop.

$$
\phi \vec{B} \cdot \overrightarrow{d l}=\mu i
$$

Where $\vec{B}$ is the magnetic flux density, $i$ is the net current and $\mu$ is the permeability. $\left[\mu=\mu_{0} \mu_{r}\right]$

According to Biot-Savart Law,

$$
d B=\frac{\mu \times i \times d l \times \sin \theta}{4 \pi r^{2}}
$$

Where:

$d l$ : is the infinitesimal length of conductor carrying the electric current i. 
$r$ : is the distance from the length element $\mathrm{dl}$ to the field point $\mathrm{P}$.

The magnetic flux is given by equation (2):

$$
\phi_{B}=\iint_{0}^{A} \vec{B} \cdot d \vec{A}
$$

Where, $A$ is the area enclosed in a given loop.

Solving the differential in (9) and then after equating in (2) we get,

$$
\phi_{B} \phi \frac{d l}{\mu A \times l}=i
$$

Ampere's law in term of reluctances is given by,

$$
\varnothing_{B}=\frac{i}{R m}
$$

Where,

$\mathrm{Rm}$ is the reluctance of the magnetic loop. $\left[\frac{A}{W_{b}}\right]\left[R_{m}=\phi \frac{d l}{\mu A \times l}\right]$

According to faradays law,

$$
\phi \vec{E} \cdot d \vec{l}=\frac{d \varnothing_{B}}{d t}
$$

Where, $\vec{E}$ is the emf or the electromotive force, $\varnothing_{B}$ is the magnetic flux.

The voltage in the coils is given by,

$$
\begin{aligned}
& v_{1}(t)=L_{p} \frac{d i_{1}(t)}{d t}+M \frac{d i_{2}(t)}{d t} \\
& v_{2}(t)=L_{s} \frac{d i_{2}(t)}{d t}+M \frac{d i_{1}(t)}{d t}
\end{aligned}
$$

The coupling coefficient $\mathrm{k}$ and inductance ratio are given by 


$$
\begin{gathered}
k=\frac{M}{\sqrt{L_{p} L_{s}}} \\
n=\sqrt{\frac{L_{s}}{L_{p}}}
\end{gathered}
$$

\section{EXPERIMENTAL WORK AND RESULTS}

For the construction of an inductive coupling circuit, the transmitter has an AG source $\left(V_{p}\right)$ and a coil with inductance $\left(\mathrm{L}_{\mathrm{p}}\right)$. The input frequency can be adjusted as per the application of usage. The greater the frequency the more the transmission efficiency. The receiver is comprised of a coil of inductance $\left(\mathrm{L}_{\mathrm{s}}\right)$ which produces an EMF for the power to be delivered to the load. As the coil Ls delivers AC voltage, a bridge rectifier is used to convert AC voltage to DC voltage which is then delivered to the load.

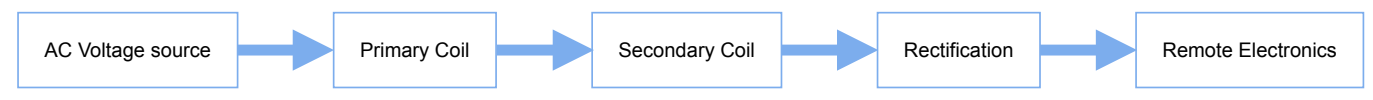

Graphic 4. Block diagram of WPT using inductive coupling. Source: (Yahaya et al., 2018).

The proposed model in Graphic 4 was implemented for charging a mobile phone.

Transmitter and receiver coils were wound on plastic forms, both the coils had the same number of turns. The core was made from steel plates and was arranged around each of the coils. The steel plates were held together by a coating of shellac.

The radius of both the coils were $0.07 \mathrm{~m}$, while the input voltage provided was $240 \mathrm{~V}$. Following results were obtained when a piece of paper was placed between the two coils and consequently the distance between the two coils was increased. A similar approach to the work done in Yahaya et al. (2018).

\begin{tabular}{|c|c|c|c|c|c|c|c|}
\hline $\begin{array}{l}\text { Distance } \\
\text { (cm) }\end{array}$ & $\begin{array}{l}\text { Input } \\
\text { Voltage } \\
\text { (V) }\end{array}$ & $\begin{array}{l}\text { Input } \\
\text { Current } \\
\text { (A) }\end{array}$ & $\begin{array}{l}\text { Input } \\
\text { Power } \\
\text { (W) }\end{array}$ & $\begin{array}{l}\text { Output } \\
\text { Voltage } \\
\text { (V) }\end{array}$ & $\begin{array}{l}\text { Output } \\
\text { Current } \\
\text { (A) }\end{array}$ & $\begin{array}{c}\text { Output } \\
\text { Power } \\
\text { (W) }\end{array}$ & $\begin{array}{c}\text { Efficiency } \\
(\%)\end{array}$ \\
\hline 0 & 208 & 0.12 & 24.96 & 22.087 & 0.881 & 19.468 & 78 \\
\hline 1 & 208 & 0.12 & 24.96 & 17.12 & 0.816 & 13.977 & 56 \\
\hline 2 & 208 & 0.12 & 24.96 & 10.935 & 0.707 & 7.737 & 31 \\
\hline
\end{tabular}

Table 2. Voltage, current and power when distance is changed. 


\begin{tabular}{|c|c|c|c|c|c|c|c|}
\hline $\begin{array}{l}\text { Distance } \\
\text { (cm) }\end{array}$ & $\begin{array}{l}\text { Input } \\
\text { Voltage } \\
\text { (V) }\end{array}$ & $\begin{array}{l}\text { Input } \\
\text { Current } \\
\text { (A) }\end{array}$ & $\begin{array}{c}\text { Input } \\
\text { Power } \\
\text { (W) }\end{array}$ & $\begin{array}{l}\text { Output } \\
\text { Voltage } \\
\text { (V) }\end{array}$ & $\begin{array}{l}\text { Output } \\
\text { Current } \\
\text { (A) }\end{array}$ & $\begin{array}{c}\text { Output } \\
\text { Power } \\
\text { (W) }\end{array}$ & $\begin{array}{c}\text { Efficiency } \\
(\%)\end{array}$ \\
\hline 3 & 208 & 0.12 & 24.96 & 6.12 & 0.57 & 3.494 & 14 \\
\hline 4 & 208 & 0.12 & 24.96 & 2.055 & 0.242 & 0.499 & 2 \\
\hline 5 & 208 & 0.12 & 24.96 & 0.12 & 0.149 & 0.0179 & 0.072 \\
\hline
\end{tabular}

As it was predicted by Akpeghagha et al. (2019), the efficiency drops drastically with the increase of distance between the two coils. Here, the input voltage and input current are the voltage and currents of the primary coil $\left(\mathrm{L}_{\mathrm{p}}\right)$, while the output voltage and output current are the voltage and currents of the secondary coil $\left(\mathrm{L}_{\mathrm{s}}\right)$.

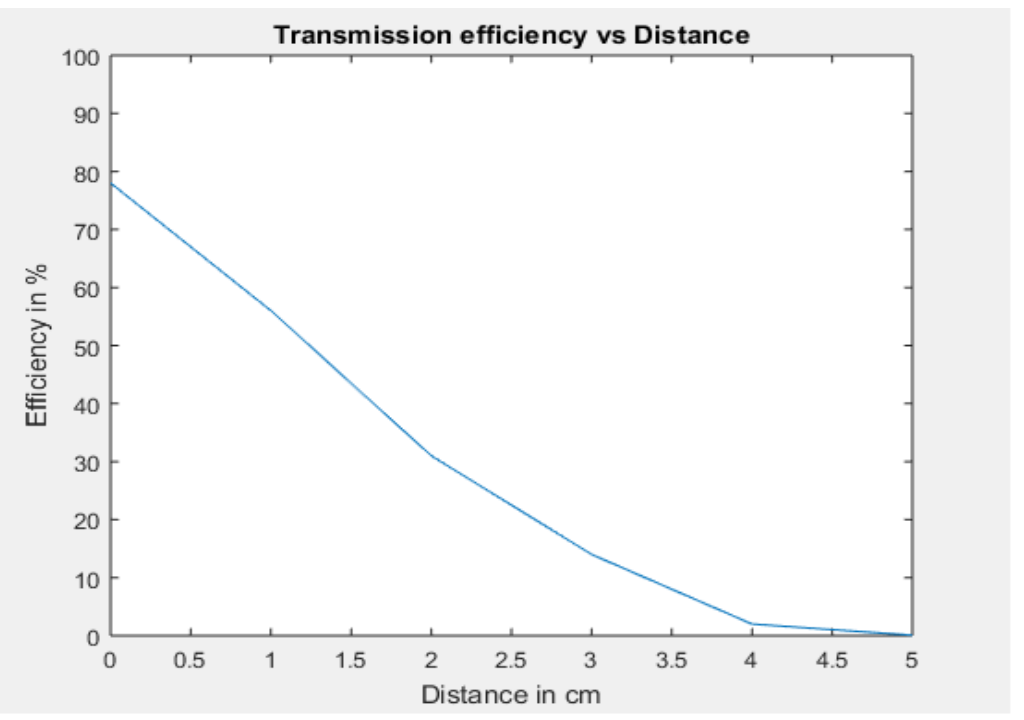

Graphic 5. Graphical representation of Transmission efficiency vs Distance.

\section{REFERENCES}

Akpeghagha, O., Iwunna, G. M., Igwele, M. M., \& Okoro, H. (2019). Witricity: Design And Implementation Of A Wireless Power Transfer System Via Inductive Coupling. Internationalfournalof Innovative ResearchandAdvancedStudies (IfIRAS), 6(4), 16-19. https:// pdfs.semanticscholar.org/508a/5b58b549248fb0c2769e2e10d6dc577ecc39.pdf?_ $\mathrm{ga}=2.107407746 .1668826937 .1585911452-626794738.1556264447$ 
Hassan, M. A., \& Elzawawi, A. (2015). Wireless Power Transfer through Inductive Coupling. Recent Advances in Circuits, 115-118. http://www.inase.org/library/2015/ zakynthos/bypaper/CIRGUITS/CIRCUITS-18.pdf

Johnson, G. L. (1990). Building the world's largest Tesla coil-history and theory. In Proceedings of the Twenty-Second Annual North American Power Symposium, Auburn, AL, USA (pp. 128-135). IEEE. https://doi.org/10.1109/NAPS.1990.151364

Van Schuylenbergh, K., \& Puers, R. (2009). Inductive powering: basic theory and application to biomedical systems. Springer Netherlands. https://www.springer.com/gp/ book/9789048124114

Yahaya, G. K. H. G. K., Adnan, S. F. S., Kassim, M., Ab Rahman, R., \& Bin Rusdi, M. F. (2018). Analysis of Wireless Power Transfer on the Inductive Coupling Resonant. Indonesian Fournal of Electrical Engineering and Computer Science, 12(2), 592599. https://www.researchgate.net/publication/327249559_Analysis_of_ Wireless_Power_Transfer_on_the_inductive_coupling_resonant 